\title{
Characteristics of adolescent attempts to manage overweight
}

\author{
Sophie Grignard ${ }^{\mathrm{a},{ }^{*}}$, Bourguignon Jean-Pierre ${ }^{\mathrm{b}}$, Born Michel $^{\mathrm{c}}$, Mairiaux Philippe ${ }^{\mathrm{a}}$, Vandoorne Chantal ${ }^{\mathrm{a}}$ \\ ${ }^{a}$ Division of Health Education and Occupational Health, School of Public Health, University of Liège, Sart Tilman BAT B23, B-4000 Liège, \\ Belgium \\ ${ }^{b}$ Division of Pediatric Endocrinology and Adolescent Medicine, Faculty of Medicine, University of Liège, Liège, Belgium \\ ${ }^{c}$ Division of Delinquency Psychology and Psychosocial Development, Faculty of Psychology, University of Liège, Liège, Belgium
}

\begin{abstract}
This study evaluates the actions taken by obese adolescents in an attempt to lose weight in relation to changes in weight. Particular emphasis is put on the context surrounding the management process. Thirty one obese adolescents aged 14-18 participated in this study. The adolescents answered a written questionnaire, took a bodysize dissatisfaction test and were interviewed. Their family physicians were interviewed by telephone.

Quantitative data concerned changes in weight and body-size dissatisfaction scores. Qualitative analysis included cases analyses and building up of synthesis variables. Loss of weight is linked with continuity of management attempts as well as with medical follow-up. The most frequent management attempt is diet. Self-image is correlated with weight. The exclusive emphasis put on diet is discussed in relation to the importance of more psychosocial factors such as self-image, denial and attraction to discontinuity. Some recommendations for the management of overweight adolescents are then outlined.
\end{abstract}

Keywords: Adolescent; Overweight; Management; Qualitative approach

\section{Introduction}

This research was initiated in the context of the creation in Liège (Belgium) of a "Adolescent Health Centre", a multi-disciplinary ambulatory Centre specifically devoted to the adolescents. A recent Belgian survey [1] has shown a $15 \%$ prevalence rate of obesity among adolescents aged 11-17 and, quite expectedly, adolescents suffering from dysorexia represent one third of the attendants seen in that centre, few of them being anorexic and the majority obese [2]. Many of these patients, however, are lost to follow up after few visits and numerous changes are seen in the actions taken by these adolescents to lose weight.

Obesity development and management may be influenced by several possible factors such as low self-esteem, family problems, lack of compliance, disorders of eating behaviour and disorders of self-image in relation to puberty [3-5]. In industrialised countries, attempts to manage obesity involve strategies beyond the control of health professionals such as special diets, drugs, exercise, .... The management of obesity in adolescents can be determined by different conditions. There are often communication difficulties or misunderstanding between adolescents and health professionals [6]. In other studies, the physicians mention some uneasiness and powerless feelings when facing adolescents [7-9]. Adolescents often find difficult to voice their requests and talk only about the somatic side of their health problems $[10,11]$. In adolescent years, however, somatic and psychosocial factors are closely related [12-14]. Finally, the family situation plays a crucial role in the development of eating disorders. In addition, the parents may hinder the development of a confidential relationship between the family physician and the adolescent $[10,15,16]$.

With these difficulties in mind, the centre co-ordinating team wished to examine the factors that are likely to bring about a better management of overweight adolescents, and a loss of weight as a result. The present research study was thus set-up to better understand the course of action followed by these adolescents in order to manage their excess weight.

The aim of this exploratory study was thus to evaluate retrospectively the different actions taken by obese adolescents in an attempt to lose weight in relation to changes in weight observed during that period. Particular emphasis was put on the context surrounding the management process. What are the characteristics of the answers the adolescent brings to his/her obesity problem? What course of action does a consultation or a series 
of consultations integrate into? What management attempts does an adolescent make without any reference to health professionals? Will some kind of management be more likely to result in a loss of weight? These are some of the questions that the research team had in mind when starting the study.

\section{Methods}

\subsection{Subjects}

This study involved 31 overweight adolescents, 14 boys and 17 girls, aged 13.3-18.3. The inclusion was based on a diagnosis of obesity made either by the school doctor $(n=25)$ or in a specialised unit-Adolescent Health Centre $(n=6)$.

\subsection{Study design}

This study involved quantitative data on age and changes in weight obtained from the medical records as well as qualitative data which were prioritised to explore the complexity of some variables including the ambivalence of adolescents in the management of overweight.

All these data were collected according to a triangulation technique, i.e. through three channels and using the following tools: (i) data from the school doctor or the specialised unit were obtained from special forms and the medical records; (ii) data from the adolescent were obtained through a self-administered questionnaire and a semi-structured interview; (iii) data from the family doctor were obtained through phone interview.

The dependent variable was weight evolution. The independent variables were derived from the qualitative analysis. Qualitative analysis was based on interviews and written questionnaires from which a detailed analysis allowed to build up secondary variables and synthesis variables (based on both the first analyses and a case study approach).

This study was approved by the Ethical Committee at the Faculty of Medicine, University of Liège and all the adolescents gave written informed consent to the study.

\subsection{Data collection}

In a first step, a form containing administrative and medical information (family and personal histories as well as reference measurements) was filled in on the basis of the adolescents' medical records. When some data were missing, further information was obtained during interview of the adolescent or the family physician.

The second step was the adolescent interview which occurred either at home or on the occasion of the systematic health visit which is compulsory every 2 years in Belgium. The adolescent interview involved three parts. Firstly, a written questionnaire was filled in to obtain information on adolescent's health status, health perception, self-esteem. In addition, this questionnaire allowed the adolescent to become familiar with the purpose of the interview. Secondly, a validated test of body-size dissatisfaction, the Contour Drawing Rating Scale [17] was used. This test consists of two series of nine contour drawings, from the slimmest one to the most obese one. The adolescent was asked to choose a silhouette he/she looked like and the silhouette he/she wanted to look like. The difference between these two silhouettes was used as an indicator of body-size dissatisfaction. A negative score indicated the wish to lose weight while a positive score suggested the wish to gain weight. The farther from zero the score is (whether positive or negative), the less satisfied the subject is. Thirdly, a semistructured interview aimed at evaluation of several aspects, including the adolescent's point of view about his/her overweight and the factors possibly involved as well as the previous attempts to manage the problem including medical or other consultations. Also, the adolescent was interviewed about his/her involvement in those attempts to lose weight and his/her assessment of the management of overweight. Information was also obtained about life within the family and relationship with peers. Finally, consent from the adolescent was asked to make a phone interview of the family physician.

The final step was a telephone interview of general practitioners (26 out of 31 adolescents) with standardised questions aiming at evaluation of the physician assessment of factors explaining obesity and the prognosis. The physicians were interviewed about the relationship with the adolescent and how the obesity problem was tackled or not in the physician's office. This phone interview allowed to delineate how the physician saw or viewed his role in the management of overweight. 


\subsection{Data analysis}

Based on the adolescent interviews, qualitative data allowed to build simple variables for body perception, health factors, assessment of causal factors and treatment, management attempts, self-esteem, adolescent involvement in making decision and social integration.

Secondary variables such as expressed uneasiness about weight, projection of future weight changes, mentioned causes of obesity, assessment of usefulness of management actions, compliance and satisfaction with treatment, self-esteem, relationship with peers and family, ... were then built on the basis of a grouping of answers to several questions scattered throughout the interview and the questionnaire.

In addition, three synthesis variables were derived from both the secondary variables and individual case analyses: types of management attempts to lose weight, continuity in the management attempts and appropriation of the management attempts by the adolescent.

The quantitative data included body mass index (BMI) and its changes during the period before interview. The BMI data were expressed as standard deviation (S.D.) scores after logarithmic transformation using the following equation: $(x-\mu) / S . D .$, where $x$ is the patient BMI, $\mu$ the mean BMI for age, and S.D. is the standard deviation of normal BMI at the patient age [18]. Based on retrospective BMI data obtained with an average period of 3.4 years before the interview, the difference in BMI SDS per year was calculated. When the difference in BMI SDS exceeded a value of -0.25 S.D., the adolescent was classified as having presented a reduction in BMI. In the other group, BMI was considered to be stable or increasing.

The relationship between BMI data and secondary and synthesis variables was studied. Statistical analysis was performed using Chi-square test, Kruskall-Wallis test and correlation test. The threshold for significance was set at $P<0.05$.

\section{Results}

\subsection{Obesity and body perception}

The mean BMI of the adolescents at the time of interview was +2.8 S.D. and ranged from +0.1 to 6.0 S.D. All the subjects were at or above +2.0 S.D. at weight evaluation several years before the study. At the time of the study, 8 out of 10 adolescents in the group with BMI reduction had a BMI SDS below +2.0 S.D. In contrast, only 2 out of 19 adolescents with stable or increasing BMI had a BMI SDS below +2.0 S.D. at the time of the study. In Fig. 1 are shown the individual differences in BMI in the two groups of adolescents. A marked increase in BMI was only seen in one adolescent while the vast majority showed stable BMI. There was obviously a continuity between the group with stable BMI and that with reduction in BMI.

It appeared from the questionnaires and interviews that all but one adolescents thought they were a bit or much too fat and 26 out of 31 would have liked to change something in their weight figures. Uneasiness was expressed by 17 adolescents who considered their weight to be a problem in everyday life, particularly due to functional consequences such as difficulties in sport practice or psychosocial consequences such as peer mockeries. For the future however, these adolescents were more concerned about possible health consequences of weight excess and not about other types of problems. The relatively small proportion of adolescents expressing uneasiness is in contrast with the content of the interviews and with the body-size dissatisfaction score which indicated that the vast majority of adolescents were concerned by weight excess. This score averaged $-2.47(n=30)$ which is low when compared with data from another recent Belgian study where a mean score of -1.24 was found in a sample of overweight adolescents [19].

At interviews, most adolescents $(n=27)$ mentioned "too much food together with inactivity" to explain that they developed obesity. At written multiple choice questionnaire, too much food and inactivity were respectively mentioned by 21 and 19 of them. Several adolescents $(n=13)$ considered that genetic factors might be involved whereas very few $(n=3)$ advocated the role of psychological problems or family problems. 
Fig. 1. Individual changes in body mass index (BMI) during the period of 3 years preceding interview of obese adolescents. The subjects are arbitrarily separated into two groups with the cut-off limit of a reduction of 0.25 $S D S$ in $B M I$ per year.

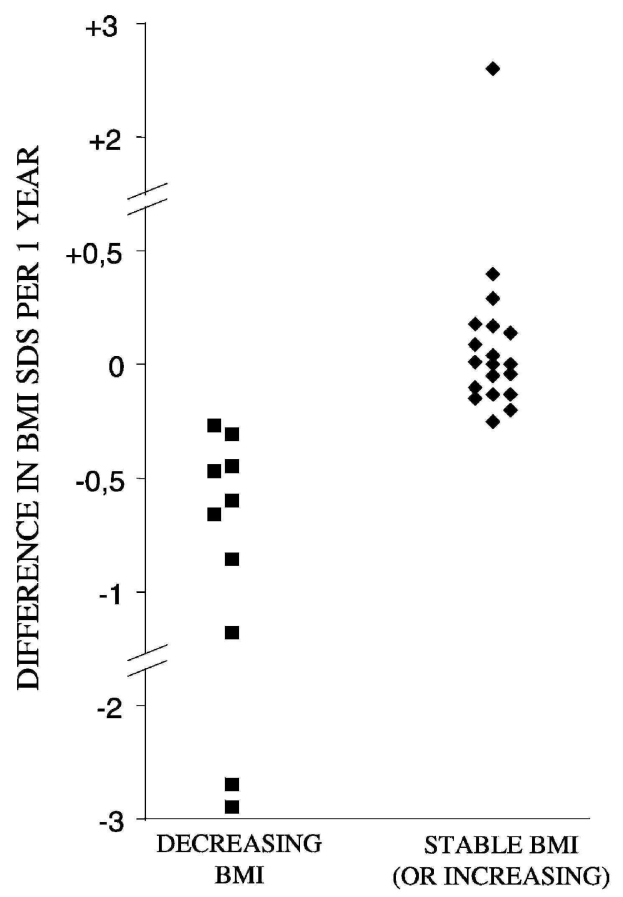

\subsection{Characteristics of the strategies of obesity management}

\subsubsection{Secondary variables}

The characteristics of the actions taken by the overweight adolescents in an attempt to lose weight were described using several secondary variables. The number of subjects is mentioned when the data were not obtained in the total group of 31 adolescents. Among the actions taken, checking weight was not commonly performed since half of the adolescents never did or only checked weight once a month. Among 29 interviewed adolescents, 20 denied the usefulness of consulting a psychologist. The management attempts involved different self-imposed actions without intervention of health care providers such as diet control, sport practice, group attendance and remedies or recipes from magazines. The consultations of professionals involved, in order of decreasing importance, the dietician, the general practitioner and the specialised physician. The results of such consultations were most often prescription of diet, alone or in combination with recommendations of life style $(n=14)$. Only four adolescents considered that they complied with those treatments or recommendations whereas half of the interviewed adolescents gave up. Most frequently, diet was the area of compliance failure. Though there was concordance between the adolescent and the physician report of compliance failure, the adolescents advocated discomfort and lack of efficacy whereas physicians referred to insufficient motivation and psychological or family difficulties. Many adolescents (17 out of 28) were not satisfied with the actions they made in an attempt to lose weight and wanted to make different actions. In contrast, 8 out of 11 adolescents who had been involved in weight management with health professionals would not have changed anything to these actions, even though most of them declared wanting to gain autonomy in the management of obesity.

\subsubsection{Synthesis variables}

Three synthesis variables were constructed to reflect the patterns of obesity management by the adolescents. Four types of management were defined, based on the interviews (Table 1). Seven adolescents did not make any action attempting to lose weight whereas 24 were involved in different actions. 
Since the case studies showed frequent interruptions in the actions made to lose weight, the continuity in the management attempts was assessed systematically. Among the 24 subjects involved in different actions, 11 showed continuity since they pursued the action initiated to lose weight. In contrast, 13 adolescents showed discontinuous management since they changed either the actions to lose weight or the professionals involved.

The third synthesis variable (assessed for 26 adolescents) was appropriation of the management attempts by the adolescent. The adolescent contribution in making decision was distributed in three levels (Table 2) showing that the majority of adolescents were involved either together with their parents $(n=11)$ or on their own $(n=10)$.

Table 1: Classification of obese adolescents according to the actions taken in an attempt to manage obesity

\begin{tabular}{|c|c|c|}
\hline Type & Definition & Subjects $(n)$ \\
\hline$\overline{\mathrm{I}}$ & No attempt to lose weight & 7 \\
\hline II & $\begin{array}{l}\text { One or several attempts without referring to health professionals } \\
\text { (self-imposed diet, sports, weight watchers, ...) }\end{array}$ & 10 \\
\hline III & Consultation of one or several health professionals about obesity & 5 \\
\hline IV & $\begin{array}{l}\text { Both attempts to lose weight without referring to health professionals } \\
\text { and consultation of one or several health professionals }\end{array}$ & 9 \\
\hline
\end{tabular}

Fig. 2. Distribution of 31 obese adolescents according to the type of attempts to manage obesity (see Table 1) and the changes in BMI observed during the 3-year period preceding interview.

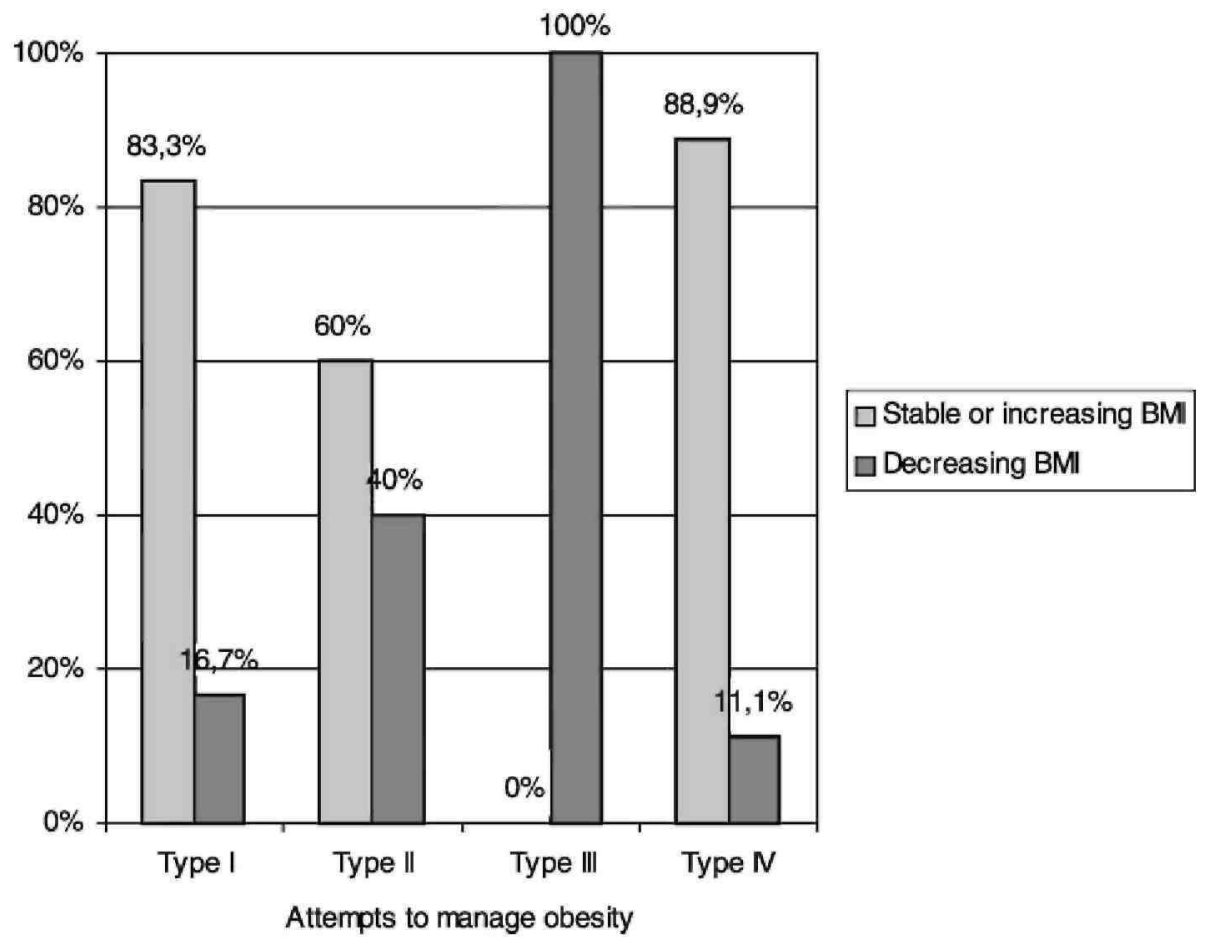


Table 2 Classification of obese adolescents according to appropriation of the attempts to manage obesity

\begin{tabular}{lll}
\hline Level & \multicolumn{1}{c}{ Definition } & Subjects $(\boldsymbol{n})$ \\
\hline 1 & $\begin{array}{l}\text { The adolescent feels to be not involved in the decisions } \\
\text { and leaves it to someone else (parents, physician) }\end{array}$ & 5 \\
2 & $\begin{array}{l}\text { Decision shared by the adolescent and the parents, joint } \\
\text { initiatives mutually agreed upon } \\
\text { Decision made primarily by the adolescent, the adolescent } \\
\text { acting alone or as the leading person }\end{array}$ & 110 \\
\hline
\end{tabular}

Fig. 3. Distribution of 24 obese adolescents in relation to continuity in the management attempts and changes in BMI seen during the 3-year period preceding interview.

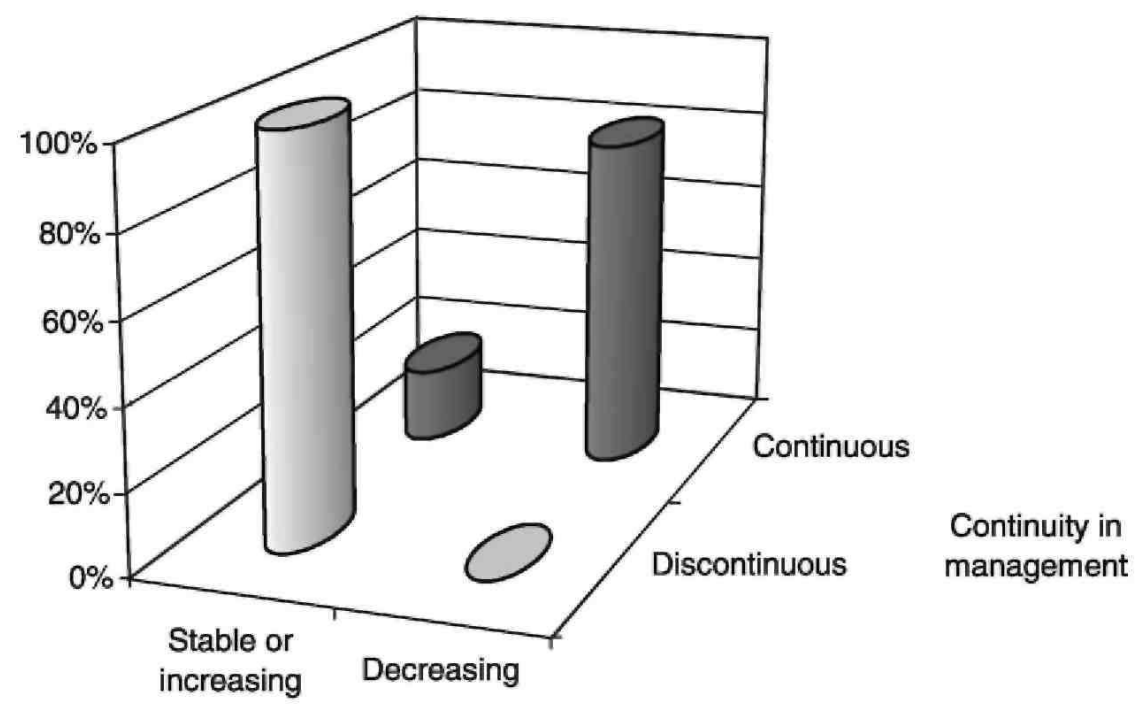

\section{Evolution of obesity}

\subsection{Correlation between the study variables}

The score of body-size dissatisfaction was significantly related to BMI of the adolescent at the time of interview $(r=0.71, P<0.0001)$. The score of dissatisfaction was also greater among adolescents with stable or increasing obesity than in those with reduced obesity $(P=0.05)$. The frequency of weight checking by the adolescent was linked to the type of management attempt, weight being regularly checked when a health professional was involved $(P=0.01)$.

The adolescents who consulted a health professional usually wanted to gain autonomy in the management of obesity. Moreover, the adolescents who did not involve health professionals in their previous management attempts either wanted to involve a health professional or were hesitating about this $(P=0.008)$.

The three synthesis variables (type of management attempts, continuity and appropriation) were not significantly related. When the correlation between these synthesis variables and the changes in BMI was calculated, two correlations were found to be statistically significant. The pattern of management attempts was significantly related with BMI changes (Fig. 2, $P=0.01$ ): a reduction of BMI was more frequently observed when management was limited to the consultation of a physician or a dietician. Conversely, BMI reduction was less likely to occur when no action was made to lose weight or when the management involved both consultation of health professionals and other management attempts.

Finally, a very strong relationship was found between the continuity in the actions made to lose weight and the reduction of obesity (Fig. 3, $P<0.001$ ). Noteworthy, the adolescent BMI at the time of interview was also linked 
to continuity of the management since higher BMIs were seen in the adolescents who showed discontinuous management $(P<0.03)$.

\section{Discussion and conclusions}

An original aspect in this study was to evaluate the actions taken by obese adolescents (involving or not a health professional) and the relationship between these actions and weight loss as assessed by the School Health Department, the adolescent him/herself and the family physician.

This retrospective evaluation of a limited number of subjects over a period of 2 years cannot pretend to understand the very changing dynamic of weight excess and its management. Instead, the aim was to study in detail a limited number of subjects to describe some behavioural and perceptual aspects in a systemic perspective. This was made possible by the use of triangulation techniques in data collection.

This study allowed to show that two characteristics of the actions taken by the adolescents in an attempt to lose weight were significantly related to weight loss: continuity in the actions and exclusive involvement of a health professional.

Although the adolescents are well aware of the role of diet and physical activity in the development of obesity, it is interesting to point out that their actions are focused on diet without paying much attention to the other aspects of lifestyle, including physical activity and even psychosocial factors. More, the psychological and familial components are massively denied by the adolescents and never involved in management proposals made by the family physician. This emphasis put exclusively on diet is raising questions because the study indicates the frequent dissatisfaction of adolescents about efficacy of dietary management and others have shown the major impact of physical activity and body perception in the development of obesity [20]. This important investment of diet with failure to lose weight may in turn account for discontinuity in the actions taken by the adolescents.

The correlation between weight and self-image has been shown in different previous studies [20,21] and is confirmed in our study based on the relationship between BMI reduction and dissatisfaction score at the Contour Drawing Rating Scale. Here, some denial may occur as well and we hypothesised that the involvement of a health care provider, which is directly related to the frequency of measuring weight, can contribute to selfacknowledgement of weight excess. As a matter of fact, it can be hypothesised that, thanks to a management by a professional, the adolescent was driven beyond the phenomenon of denying his/her problem.

Though losing weight and improving body image are closely linked, it is not possible to delineate which among these two factors is the cause and which one is the consequence. Here, the involvement of the adolescent in regular physical activity practice can have some influence not only on weight but on self-image as shown by others [22]. Another issue is as to whether the positive impact of losing weight and improving self-image has any influence on the long-term weight control.

\subsection{Practice implications}

Based on our data, we could propose that weight management programs should take into account not only body image and self-esteem but also the attraction to discontinuity which is inherent to adolescence. In the management of overweight, it might be important that professionals propose several actions not only involving different aspects (physical activity, diet, psychosocial or familial components) but also a variety based on duration of the management and the different professionals involved in the management. The interest of nonprofessional actions should not be underestimated. Such actions may allow to take temporarily some distance from the health professionals.

In future studies, a prospective longitudinal follow-up of obese adolescents could allow to better delineate the respective contribution of professional and non-professional management and their contribution to the adolescent capacity to lose weight. This could be done by studying in a more elaborate way the category of subjects who make at one and the same time "profane" and "professional" attempts. Such a follow-up could also allow to better understand the links between physical activity, self-esteem, self-image and loss of weight. Finally, it would maybe help clarifying the question of continuity/discontinuity of the attempts. 


\section{Acknowledgements}

This research was funded by the French-speaking Community of Belgium (grant no. 98.51/402). The authors express gratitude to F. Glowacz and X. Lechien for their assistance in the designing of the study. Their gratitude also goes to M. Vroonen for the English edition of the manuscript, as well as to the adolescents for their participation.

\section{References}

[1] Piette D, Prevost M, Boutsen M, De Smet P, Leveque A, Barette M. Vers la santé des jeunes en l'an 2000 [Towards health of young people in year 2000]. Bruxelles: ULB-PROMES; 1997.

[2] Bourguignon JP, Grignard S, Glowacz F, Walthéry C, Vandoorne C, Boden S. Motivations et apports d'une prise en charge ambulatoire pluridisciplinaire de la santé des adolescents [Motivations and contributions of a multidisciplinary ambulatory management of adolescent health]. Bull Educ Patient 2000;19(3): 126-9.

[3] Thombs DL, Colleen AM, MacLaughlin ML. Expectancies, self-esteem, knowledge, and adolescent weight reduction behaviour. JNE 1998;30(2): 107-13.

[4] Hoffmann-Muller B, Amstad H. Body image, weight and eating behavior in adolescents [abstract]. Schweiz Rundsch Med Prax 1994;83:1336-42.

[5] Buddeberg-Fischer B, Klaghofer R, Reed V. Associations between body weight. Psychother Psychosom 1999;68:325-32.

[6] Deschamps JP. Ces jeunes sont sans soins ou la non-santé des adolescents et jeunes adultes en France [These young people are without care or the non-health of adolescents and young adults in France]. Rev Fr Aff Soc 1987;41:43-57.

[7] Blum R. Physicians' assessment of deficiencies and desire for training in adolescent care. J Med Educ 1987;62:401-7.

[8] Ryan SA, Millstein SG, Greene B, Irwin CE. Utilization of ambulatory health services by urban adolescents. J Adolesc Health 1996;18:192-202.

[9] Verron M, Angel P. Pathologies somatiques à l'adolescence, repères statistiques [Somatic pathologies in adolescence, statistical guide marks]. Adolescence 1985;3:239-51.

[10] Michaud A, Narring F, Dubois-Arber F, Paccaud F Recherche romande sur la santé des adolescents de 15 à 20 ans [Swiss research about 15-to-20-year-old adolescents]. Schweiz Med Wochenschr 1993;123:1883-95.

[11] Alvin P. La consultation de l'adolescent [Consultation with adolescents]. Gaz Med 1988;95:31-7.

[12] Jeammet P, Braconnier A, Choquet M, Houllemare L, Huerre P, Jacquet Y, et al. Adolescences. Paris: Fondation de France et AGF; 1993. p. 9-21.

[13] Choquet M, Ledoux S. Les troubles fonctionnels de l'humeur comme indicateurs de santé à l'adolescence [Functional and humor disorders as health indicators in adolescence]. Arch Fr Pediatr 1991;48: 99-105.

[14] Burner M. Le devenir de la plainte dans la relation médecin-malade [What complain becomes in the doctor-patient relation]. Psy Med 1989;21:318-9.

[15] Alvin P. L'examen de l'adolescent (1) [Consultation with adolescents]. Concours Med 1986;108:1977-81.

[16] Alvin P. L'examen de l'adolescent (2) [Consultation with adolescents]. Concours Med 1986;108:2150-4.

[17] Thompson MA, Gray JJ. Development and validation of a new body-image assessment scale. J Pers Assess 1995;64:258-69. 
[18] Rolland-Cachera MF, Bellisle F, Deheeger M, Pequignot F, Sempe M. Influence of body fat distribution during childhood on body fat distribution in adulthood: a two-decade follow-up study. Int J Obesity 1990;14:473-81.

[19] Bonhomme M. Estime de soi et insatisfaction corporelle chez les adolescents en excès de poids (mémoire de fin d'études) [Self-esteem and body-size dissatisfaction in overweight adolescents]. Liège: Université de Liège; 1996.

[20] Gordon-Larsen P. Obesity-related knowledge, attitudes, and beha-viours in obese and non-obese urban Philadelphia female adolescents [abstract]. Obes Res 2001 ;9(2): 112-8.

[21] Cameron JW. Self-esteem changes in children enrolled in weight management programs [abstract]. Issues Compreh Ped Nurs 1999;22(2-3):75-85.

[22] MacKinnon CA. Feminism unmodified, discourses on life and law. London: Harvard University Press; 1997. p. 121sqq. Cited in: Bourdieu P. La domination masculine [Male domination]. Paris: Seuil; 1998. p. 74. 